\title{
La publicidad actual: retos y oportunidades
}

\author{
José MARTÍ PARREÑO ${ }^{1}$ \\ Universidad Europea de Madrid \\ Yolanda CABRERA GARCÍA-OCHOA ${ }^{2}$ \\ Universidad Europea de Madrid \\ Joaquín ALDÁs MANZANO ${ }^{3}$ \\ Universitat de València
}

\begin{abstract}
RESUMEN:
El entorno publicitario ha cambiado considerablemente en los últimos años: nuevos medios y herramientas, nuevos soportes, nuevos comportamientos de los consumidores, nuevas necesidades de los anunciantes... Estos y otros factores del macro entorno están obligando a los agentes implicados en el sector publicitario a emprender nuevos caminos y estrategias con las que alcanzar de forma más eficaz sus objetivos. Las agencias de publicidad en concreto han tenido que evolucionar considerablemente en los últimos años para poder satisfacer unas necesidades crecientes de sus clientes. La optimización de recursos, incluidos los económicos, la especialización o la capacidad para ofrecer nuevos servicios demandados por sus clientes son sólo algunos de los factores que plantean nuevos escenarios con importantes retos pero también con interesantes oportunidades. Algunos temas relevantes que emergen de estos nuevos escenarios incluyen la personalización de los mensajes, la interactividad, el papel cambiante del consumidor a la hora de consumir estos mensajes y nuevas herramientas más eficaces en un entorno publicitario saturado. Este trabajo analiza los principales retos y oportunidades que se plantean en la actualidad a la hora de desarrollar comunicaciones publicitarias más eficaces.
\end{abstract}

PALABRAS CLAVE: publicidad; eficacia publicitaria; tecnología

TITLE: Nowadays advertising: challenges and opportunities

ABSTRACT:

Advertising landscape has strongly changed during these last years: new media and new advertising tools, new means of advertising, new consumer behaviors, new marketers' needs... All these and other factors of the macro-environment are contributing to start new strategies - by all the agents involved in nowadays advertising- in order to achieve a much more effective way to reach advertising objectives. Advertising agencies, especially, have been encouraged to evolve during these last years in order to satisfy their clients' increasing needs. Optimization of the available resources - including the economic ones- specialization, or the ability to offer new services demanded by their clients are just a few of the new factors that are drawing new scenarios presenting new challenges but also new opportunities to advertising practice. Relevant issues in these new scenarios include message personalization, interactivity, the evolving role of consumer when consuming these messages and new tools being more effective in a cluttered advertising environment. This

1 Profesor del Departamento de Empresa. Universidad Europea de Madrid. E-mail: jose.marti@uem.es

2 Profesora del Departamento de Empresa. Universidad Europea de Madrid. E-mail: yolanda.cabrera@uem.es

3 Profesor Titular del Departamento de Comercialización e Investigación de Mercados. Facultad de Economía. Universitat de València. E-mail: joaquin.aldas@uv.es 
paper analyzes some of these challenges and opportunities that advertisers must face to develop more effective advertising communications.

KEY WORDS: advertising, advertising effectiveness, technology

\section{Introducción}

La publicidad ha experimentado en los últimos 10 años cambios importantes que no sólo han afectado al modo de conceptualizar, planificar y desarrollar los mensajes publicitarios sino que incluso han llegado a cuestionar la propia función y objetivos de la publicidad en la actualidad ${ }^{4}$. No sólo han surgido nuevos formatos y estrategias (banners, publicidad contextual, campañas SMS, branded content, realidad aumentada, plinking...) sino que se ha cuestionado el papel desempeñado por los agentes clásicos (agencias de publicidad, agencias de medios) e incluso si estaban suficientemente preparados para ofrecer las nuevas soluciones demandadas por sus clientes. Baste recordar el debate en torno a agencias especializadas versus agencias de servicios integrales (las denominadas full services shops en Internet y todas las categorizaciones posteriores como agencias $360^{\circ}$, agencias 2.0 , etc. $)^{5}$ o el debate en torno a la función estratégica de las agencias de publicidad y su migración hacia un modelo de comunicaciones de marketing integradas ${ }^{6}$. Todos estos, y otros factores, han sido provocados, o cuanto menos modelados de manera importante, por un cambio tecnológico y social liderado por Internet (dinamizado ahora por Internet móvil) que, en el marco de la sociedad de la información, está cambiando a pasos agigantados el modo en el que nos comunicamos, nos relacionamos, trabajamos y consumimos (incluidos los mensajes publicitarios).

El presente trabajo tiene como objetivo principal realizar una aproximación teórica a los principales factores tecnológicos, en especial en el marco de Internet, que han acaecido en los últimos 10 años y analizar su impacto, desde el punto de vista de la eficacia publicitaria, en el desarrollo de los mensajes publicitarios actuales. Para ello, en un primer apartado se analiza brevemente la evolución tecnológica y social del contexto publicitario con el objetivo de identificar las principales debilidades-amenazas y fortalezas-oportunidades que plantea al desarrollo de las comunicaciones publicitarias actuales. A continuación se analizan detenidamente esas debilidades-amenazas (retos) y fortalezas-oportunidades (oportunidades). En el apartado de conclusiones se incorporan las principales implicaciones directivas que deben ser tenidas en cuenta a la hora de planificar y desarrollar comunicaciones publicitarias que busquen incrementar la eficacia publicitaria en la actualidad.

4 RIES, A. y RIES, L. (2003): La caída de la publicidad y el auge de las RR.PP., Barcelona, Ediciones Urano (colección Empresa Activa) ( $1^{\circ}$ edición 2002, HarperCollins)

5 Para una aproximación más extensa a este debate consultar: Buzzi, G. A. (Ed.) (2009): El modelo de la Nueva Agencia, http://creativecommons.org/licenses/by-nc-nd/2.5/ar/ Web visitada el 6/3/2011

6 MARTí, J. y MuÑOZ, P. (2008): Engagement Marketing: una Nueva Publicidad para un Marketing de Compromiso, Madrid, Finantial Times/Prentice Hall. 


\section{El contexto publicitario actual: una perspectiva tecnológica}

El contexto publicitario actual empezó a conformarse en 2001 con dos hechos que quizás no han recibido la atención necesaria pero que jugaron un papel determinante en el despegue de Internet como medio publicitario. Estos dos hechos fueron la aparición de la tecnología streaming y el software Macromedia ${ }^{\circledR}$ Flash $^{7}$ (Martí, 2002). De la mano de un software de producción audiovisual y una tecnología de difusión que optimizaba el escaso ancho de banda de la época ${ }^{8}$, Internet, y en concreto la Web, se hizo plenamente audiovisual. Los anunciantes ya no veían sus esfuerzos de comunicaciones limitados a imágenes estáticas o a simples GIF animados sino que podían elaborar mensajes más complejos y atractivos que incluían sonido y animaciones (además de interactividad, característica distintiva del medio que lo posicionaba frente a otros medios como la radio o la televisión). El creciente interés de los anunciantes y de otros agentes implicados en el incipiente sector de la publicidad online (desarrolladores, redes de publicidad, etc.) pronto convirtieron el medio en un vivero de experimentación de nuevos formatos y estrategias publicitarias. Surgieron todo tipo de formatos gráficos (rascacielos, pop-ups, interstitials...) $\mathrm{y}$ estrategias (advertainment, advergaming, aplicaciones publicitarias, posteriormente, widgets, estrategias de posicionamiento en buscadores, etc.). Es en este contexto cuando se empieza a hablar de una creciente fragmentación de las audiencias (aunque este proceso ya se había iniciado anteriormente con el nacimiento de la televisión por cable). La web atrae a un número cada vez mayor de usuarios que no muestran comportamientos e intereses tan homogéneos como en otros medios. Los soportes no se cuentan por decenas sino por millones y aunque en un principio los llamados portales generalistas siguen aglutinando a buena parte de los usuarios, la microfragmentación de las audiencias en un futuro a muy corto plazo es contemplada como algo inevitable. Esta fragmentación se acrecentará en los años posteriores en otros medios como la televisión (en especial a partir del nacimiento de la TDT), siendo también una consecuencia de un consumo de medios cada vez más complejo por parte de los usuarios, que van incorporando cada vez más medios a su cartera (videoconsolas, telefonía móvil, etc.). Es en este contexto cuando los anunciantes se dan cuenta de que, como consecuencia de esta fragmentación, llegar a sus públicos de interés de manera eficaz va a resultar cada vez más difícil. Por otra parte, la saturación publicitaria empieza a ejercer presión sobre unos consumidores que no pueden, ni voluntaria ni involuntariamente, procesar el creciente número de impactos diarios: cuñas radiofónicas, anuncios impresos, spots televisivos, banners en sitios web, vallas publicitarias en videojuegos, SMS publicitarios en su móvil...

7 Martí, J. (2002): Publicidad y entretenimiento en la web: Estrategias, Formatos y Tipologías de Advertainment. Tesis Doctoral, Universidad Politécnica de Valencia.

8 Lejos aún de la popularización de la banda ancha, del ADSL, del cable y de las tarifas planas. 
A partir de 2006 empieza a consolidarse una nueva evolución de las redes digitales, los denominados medios sociales, que se constituyen en el eje central de la web 2.0, una web que:

[...] democratiza el conocimiento y la participación de los usuarios en el medio; en la que se incentiva la co-creación de los contenidos que se generan en ella; y que permite el trasvase de estos contenidos entre los diferentes medios digitales interactivos al servicio del usuario (Internet, telefonía móvil, etc.)"9".

Este nuevo modelo de comunicación está compuesto por objetos (textos, vídeos, imágenes, etc.) que «conectan a personas a través de numerosos hiperenlaces en un nuevo modelo de narrativa interactiva construida mediante fragmentos y pastiches que el usuario recompone a través de su navegación por la web» ${ }^{10}$ y que tiene importantes consecuencias para la comunicación publicitaria (quizás la consecuencia principal sea la dilución del mensaje en manos de los consumidores).

Junto a este primer análisis de factores que parecen plantear, a priori, importantes retos a la eficacia publicitaria actual, se puede efectuar un análisis de factores relacionados que parecen actuar al otro lado de la balanza, esto es, favoreciendo la eficacia. Así, la multiplicidad de medios y soportes permite incrementar la conveniencia de los consumidores (permitiéndoles acceder a los mensajes en el momento, modo y lugar que les resulte más adecuado a sus necesidades). La utilización de las bases de datos (cuyo poder de análisis se ha incrementado notablemente como consecuencia de los datos obtenidos de los registros como usuario de los sitios web) permite empezar a personalizar los mensajes aumentando de este modo su relevancia para el consumidor. Además, la incorporación de la interactividad (primero en la web, después en la telefonía móvil y, finalmente, en la televisión) desencadena la participación e implicación de los consumidores con los mensajes. Por otra parte, si la evolución de los medios hacia plataformas de aplicaciones (concepto 2.0) planteaba retos a los mensajes, no es menos cierto que también plantea oportunidades. Quizás las dos más importantes son la colaboración de los usuarios en la creación de los mensajes (compromiso) y la difusión (viralidad) de los mismos. Asimismo la digitalización ha permitido una importante reducción de costes a la hora de difundir unos mensajes publicitarios, cuya naturaleza de bits y no de átomos, facilita su reproducción y difusión (aumentando de esta manera la competitividad de los anunciantes). Finalmente, las redes digitales han posibilitado ampliar considerablemente el alcance de estas comunicaciones, alcanzando mercados globales y facilitando economías de escala. Estos factores, que son analizados en los siguientes apartados, se recogen en la tabla 1.

No es objetivo de este trabajo analizar otros aspectos estructurales o del mercado (por ejemplo, la irrupción de nuevos agentes tecnológicos como Microsoft o Google en el sector publicitario) pero no hay que olvidar que la conformación del

9 MARTí, J. (2011): Marketing y Publicidad en Internet. Básico. $2^{\text {a }}$ Ed., Madrid, Starbook, 206.

10 Ibídem. 
contexto publicitario actual se ha visto influenciada por otros factores importantes, no sólo el tecnológico, como la debilitación de los medios tradicionales como canal de comunicación, la paulatina migración de los presupuestos de marketing de la publicidad a otras herramientas de las comunicaciones de marketing ${ }^{11}$ o los cambios experimentados en el comportamiento del consumidor ${ }^{12}$. Estos y otros cambios, como la internacionalización de los mercados y la globalización, no han hecho más que ahondar en el convencimiento de que nuevos escenarios de creciente complejidad, la necesidad de alcanzar sinergias y economías de escalas y el adoptar una perspectiva glocal de las comunicaciones de marketing, requieren nuevos modelos, como el de las comunicaciones de marketing integradas ${ }^{13}$, necesarios para incrementar la eficacia de las comunicaciones publicitarias actuales.

\begin{tabular}{|c|c|}
\hline $\begin{array}{l}\text { DEBILIDADES } \\
\text { - } \quad \text { Fragmentación de audiencias. } \\
\text { - Saturación publicitaria. } \\
\text { - Pérdida de control. }\end{array}$ & \begin{tabular}{l} 
AMENAZAS \\
\multicolumn{1}{c}{ AME } \\
- \\
- $\quad$ Pérdida de atención. \\
- $\quad$ Dilución del mensaje.
\end{tabular} \\
\hline $\begin{array}{l}\text { FORTALEZAS } \\
\text { - } \text { Multiplicidad de medios. } \\
\text { - } \text { Personalización. } \\
\text { - Interactividad. } \\
\text { - } \text { Colaboración. } \\
\text { - } \text { Reducción de costes. } \\
\text { - Alcance. }\end{array}$ & $\begin{array}{ll} & \text { OPORTUNIDADES } \\
\text { - } & \text { Conveniencia. } \\
\text { - } & \text { Relevancia. } \\
\text { - Implicación. } \\
\text { - Compromiso y viralidad. } \\
\text { - Competitividad. } \\
\text { - } \text { Escalabilidad. } \\
\end{array}$ \\
\hline
\end{tabular}

Tabla 1. Análisis DAFO del macro entorno tecnológico publicitario actual.

Fuente: elaboración propia

\section{Principales retos de la comunicación publicitaria actual}

\subsection{Fragmentación de audiencias}

Mientras que en 1965 se podía llegar al 80\% de los adultos de los EE.UU. con 3 spots de televisión de 60", en 2002 eran necesarios 117 spots en horario prime time para obtener el mismo alcance ${ }^{14}$. Es un hecho constatado que las audiencias ya

\footnotetext{
11 LeVInSON, J. C. (2001): «Integrated Marketing», Executive Excellence, 18 (1)1, 9-10

12 CAywood, C. (1997): «Integrated Marketing Communication», Proceedings de la Seoul International Advertising Conference. Seúl, Korea Federation of Advertising Associations.

13 Schultz, D. E. y Kitchen, P.J. (2000): Communicating Globally: An Integrated Marketing Approach. Nueva York, Macmillan Basingstoke.

14 Stengel, citado en MARTí, J. y MuÑoz, P. (2008): Engagement Marketing: una Nueva Publicidad para un Marketing de Compromiso, Madrid, Finantial Times/Prentice Hall.
} 
no están reunidas en torno a la radio o la televisión. En una familia media actual, podemos encontrar al padre viendo un programa de televisión, a la madre en otra estancia viendo otro programa, a la hija navegando por Internet en su habitación y al hijo jugando a los videojuegos. Muy pocos eventos (si pensamos en programas de televisión, por ejemplo) son ya capaces de congregar a grandes audiencias. La gran amenaza desde el punto de vista de la eficacia del mensaje se plantea pues en una etapa inicial en la que se corre el riesgo de no llegar al público de interés. Además, en su complejo, y a veces caprichoso, consumo de medios, el consumidor actual "salta" de un medio a otro haciendo cada vez más difícil su localización. En este sentido, el auge de herramientas de branded content ${ }^{15}$, cuyo objetivo es atraer a los consumidores hacia los mensajes con una promesa de entretenimiento, parece confirmar que resulta más sencillo generar audiencias que perseguirlas.

\subsection{Saturación publicitaria}

El incremento exponencial de medios y soportes se ha traducido en una creciente superabundancia publicitaria. La cifra de impactos publicitarios diarios a los que está expuesto el ciudadano medio oscila entre los 1.000 y los 5.000, dependiendo de la metodología de medición empleada ${ }^{16}$. Evidentemente esta situación plantea una seria amenaza para la eficacia publicitaria actual y es la creciente dificultad de captar la atención del consumidor en un contexto en el que el ruido generado por otras marcas y mensajes, que compiten por esa misma atención, provoca que los mensajes se solapen e interfieran. En el marco de la denominada economía de la atención, se ha destacado especialmente el valor de la atención como un recurso cada vez más escaso de la sociedad de la información ${ }^{17}$. Otra consecuencia de la saturación publicitaria, más perjudicial todavía para la eficacia de los mensajes, es el rechazo intencionado que una intrusión extrema puede desencadenar en el consumidor. Conocidos comportamientos del consumidor como el zapping televisivo son buena prueba de este rechazo. Por otra parte, innovaciones tecnológicas como los DVR (Digital Video Recorder), con sus funciones de grabado de programación televisiva a la carta (incluyendo la eliminación de los anuncios), los filtros antispam utilizados en el correo electrónico y otras herramientas de eliminación de la publicidad no deseada nos advierten de la amenaza que supone la saturación publicitaria para la eficacia de los mensajes (conduciéndonos de la atención a la des-

15 Lehu, J. M. (2007): Branded Entertainment: Product Placement \& Brand Strategy in the Entertainment Business, Kogan Page, Londres y Filadelfia; MARTí, J. (2010): Funny Marketing: consumidores, entretenimiento y comunicaciones de marketing en la era del branded entertainment, Madrid, WoltersKluwer.

16 La revista Frontline, por ejemplo, estimó en 2001que estábamos expuestos a unas 3.600 marcas al día.

Goldhaber, M. H. (1997): «The Attention Economy and the Net», First Monday, 2 (4). 
atención y de ésta al rechazo). En este sentido, la teoría de usos y gratificaciones $^{18}$ puede ofrecer un útil marco de referencia para conocer las necesidades informativas, sociales y de entretenimiento que puede satisfacer la publicidad y que pueden ser utilizadas para captar la atención del consumidor.

\subsection{Pérdida de control}

La pérdida de control del mensaje publicitario por parte del emisor (ya sea un anunciante, una institución, un organismo gubernamental, etc.) es quizás la debilidad más importante que presenta el contexto publicitario actual. En una época de marcado apropiacionismo intelectual, que fomenta los entornos colaborativos (como las culturas de código abierto) y que asiste a un auge del protagonismo de las culturas vernáculas como la cultura fan $^{19}$, los mensajes son reinterpretados, recodificados, mezclados (fenómeno de las mash-ups) e incluso distorsionados por los consumidores. Tal y como se ha señalado, «la gente normal toma el control de la producción cultural en sus propias manos» ${ }^{20}$, y esto también incluye la producción publicitaria. En el caso de los productos publicitarios, los diferentes procesos de tamizado y transformación efectuados por los consumidores pueden poner en serio peligro el concepto original del mensaje, pudiendo conducir a la confusión, mal interpretación o equívoco del mensaje cuando no a su dilución total. Los resultados prácticamente profesionales que ofrece el software de edición y retoque digital actual a los consumidores pueden incluso plantear problemas a los anunciantes al ponerse en circulación contenidos supuestamente emitidos por las marcas cuya verdadera fuente resulta en muchas ocasiones difícil de identificar. Basten como ejemplo de estas situaciones la falsa campaña promocional del disco de Bryan Adams, Room Service, o los experimentos con Coca-Cola Light y Mentos realizados por los norteamericanos Grobe y Voltz ${ }^{21}$. En este último caso, la portavoz de Coca-Cola Light calificó los vídeos en los que se mostraban los experimentos como una "locura" que no encajaba con la personalidad de la marca ${ }^{22}$. Mención aparte merecen otras acciones de apropiacionismo intencionadamente malévolo por parte de activistas anti-publicidad.

18 Katz, E., Gurevitch, M. y HaAs, H. (1973): «On the Use of the Mass Media for Important Things», American Sociological Review, 38 (2), 164-181.

19 Fiske, J. (1992): «The Cultural Economy of Fandom», En Lewis, Lisa A. (Ed.): The Adoring Audience. Londres, Routledge.

20 MARKman, K. M. (2005): «Star Trek, Fan Film, and the Internet: Possibilities and Constraints of Fan-Based Vernacular Cultures»», ponencia presentada en la Popular Communication Division de la Annual Convention of the International Communication Association, 30 de Mayo, New York, NY, 2.

21 MARTí, J. (2010): Funny Marketing: consumidores, entretenimiento y comunicaciones de marketing en la era del branded entertainment, Madrid, Wolters-Kluwer.

22 Vranica, S. y Terhune, C. (2006): «Mixing Diet Coke and Mentos makes a gusher of publicity», 12 de Junio, B1, http://online.wsj.com/article_print/SB115007602216777497.html Web visitada el $21 / 2 / 2011$. 


\section{Principales oportunidades de la comunicación publicitaria actual}

\subsection{Multiplicidad de medios}

Los consumidores actuales tienen acceso a un elevado número de medios (impresos, verbales y audiovisuales) que pueden utilizar según su conveniencia y necesidades. Cada nuevo medio que aparece incorpora las características de los medios anteriores $^{23}$ en un entorno de creciente riqueza de medios ${ }^{24}$ que permite clasificar a los diferentes medios en un continuo «en función de su capacidad para producir retroalimentación inmediata, albergar información múltiple, capacidad de personalización de la información, y comunicar mensajes complejos» ${ }^{25}$. Si la radio contiene mensajes verbales y los medios impresos textos e imágenes, el cine y la televisión hibridan imágenes y mensajes verbales, y, finalmente, Internet incorpora la interactividad y una retroalimentación en tiempo real. Esta multiplicidad de medios ofrece a los anunciantes la posibilidad de utilizar múltiples códigos y lenguajes con los que dirigir al consumidor diferentes mensajes en función de sus objetivos y contextos. La utilización sinérgica de estos múltiples medios al alcance del consumidor está relacionada no sólo con la complejidad del mensaje que pueden ofrecer, ajustándose a las necesidades en cada momento, sino también con el concepto de accesibilidad del consumidor al mensaje, entendida esta accesibilidad como un concepto multidimensional «relacionado con el acceso físico a la fuente, la interfaz de acceso y la habilidad para recuperar físicamente información potencialmente relevante ${ }^{26}$. Es decir, cada medio satisfará una conveniencia de uso en función de las necesidades del consumidor (por ejemplo, ubicuidad en el caso de la telefonía móvil). A pesar de las oportunidades que ofrece esta multiplicidad de medios para incrementar la eficacia publicitaria no hay que olvidar que, desde un punto de vista publicitario, también se ha señalado que

dado que los medios más ricos también tienden a exigir costes cognitivos (y de otro tipo) mayores en los consumidores, surge la cuestión de qué tipo de información

23 Rodgers, S. y THORson E. (2000): «The Interactive Advertising Model: How Users Perceive and Process Online Ads», Journal of Interactive Advertising, 1 (1), http://jiad.org/vol1/no1/rodgers Web visitada el 23/6/2007.

24 DAFT, R. L. y LENGEL, R.H. (1986): «Organizational information requirements, media richness and structural design», Management Science, 32 (5), 554-571.

${ }_{25}$ PAVlou, P. A. y Stewart, D. W. (2000): «Measuring the Effects and Effectiveness of Interactive Advertising: A Research Agenda», 1 (1), http://www.jiad.org/vol1/no1/pavlou/index.htm Web visitada el 23/5/2007, 7 .

26 CulnAN, M. J. (1985): «The dimensions of perceived accessibility to information: Implications for the delivery of information systems and services», Journal of the American Society for Information Science, $36,302-308,302$. 
desean los consumidores y hasta qué punto un mensaje publicitario se ajusta a un grado particular de riqueza de medios ${ }^{27}$.

Es decir, el ajuste medio/mensaje con la conveniencia/necesidad del consumidor resultará determinante para incrementar la eficacia de la comunicación publicitaria.

\subsection{Personalización}

Internet significó alcanzar, al menos en la teoría, el paradigma de la comunicación publicitaria ideal: dirigirnos a la persona adecuada, en el momento adecuado, a través del mensaje adecuado. Los datos obtenidos mediante los conocidos registros de usuarios de los sitios web, aportaban ingentes cantidades de datos relacionadas con los perfiles demográficos y psicográficos de los usuarios. Completados con el comportamiento online (hábitos de navegación, sitios visitados, duración de las visitas, información o contenidos accedidos así como otras actividades diversas) estos perfiles auguraban el poder de dirigirse a cada usuario de manera totalmente personalizada (publicidad one to one). Internet móvil ha expandido estas posibilidades y ahora, además, los anunciantes pueden dirigir sus mensajes a consumidores que están en el lugar adecuado gracias a la utilizando de servicios de geolocalización. En un marco ideal, un anunciante que detecta la presencia de un consumidor cerca de su establecimiento y que sabe que este consumidor está interesado en uno de los productos que comercializa puede enviarle un mensaje publicitario que se ajuste a sus preferencias (tipo de mensaje, tono del mensaje, tipo de incentivo que puede resultar más eficaz...). La empresa sueca de equipamiento deportivo Playground, por ejemplo, ha utilizado herramientas de geolocalización para dirigir anuncios de 70 modelos de abrigos en función de las diferentes condiciones meteorológicas de un día concreto en diferentes ciudades suecas ${ }^{28}$. El incrementar la relevancia de los mensajes publicitarios para el consumidor mediante la personalización de mensajes que se ajusten a sus necesidades e intereses supone quizás la mejor oportunidad para incrementar la eficacia de la publicidad actual. Un marco de trabajo que obliga a reformular un marketing de masas masivo a un marketing de masas de un solo consumidor (un concepto relacionado con los procesos de prosumición).

\subsection{Interactividad}

El concepto de interactividad es complejo y se ha definido desde diferentes campos, adoptando pues distintas perspectivas ${ }^{29}$. Steuer, por ejemplo, define la interac-

27 Pavlou, P. A. y Stewart, D. W. (2000): «Measuring the Effects and Effectiveness of Interactive Advertising: A Research Agenda», 1 (1), http://www.jiad.org/vol1/no1/pavlou/index.htm Web visitada el 23/5/2007, 7 .

28 Southgate, D. (2009): «Targeting Online Ads: Aim for the Bulls-eye or Focus on Hitting the Target?», Millward Brown Point of View.

29 MacMillan, S. J. y Hwang, J. S. (2002): "Measures of Perceived Interactivity: An Exploration of the Role of Direction of Communication, User Control, and Time in Shaping Perceptions of Interactivity», Journal of Advertising, 31 (3), 29-57. 
tividad como «la capacidad de los usuarios para participar y modificar la forma y el contenido de un entorno mediado en tiempo real» ${ }^{30}$. Es decir, en el contexto de los mensajes publicitarios, el grado de interactividad determinaría la capacidad de participar en ellos y modificarlos mientras son consumidos. Otorgar a los consumidores la capacidad de interactuar con los mensajes publicitarios esté directamente relacionado con apelar al grado de implicación que queremos que desarrollen con ellos. En la medida en que se permita un mayor grado de interacción con ellos se incrementará la implicación con el mensaje puesto que la implicación tiene una dimensional comportamental que motiva a la acción ${ }^{31}$. También se han señalado los efectos persistentes de la implicación, como un estado con una intensidad y dirección determinadas, que pueden conducir a dedicar un mayor tiempo a examinar diferentes alternativas, a utilizar estrategias de codificación más elaboradas así como a incrementar la respuesta cognitiva total y dirigida hacia el objeto desencadenante de esa implicación del consumidor ${ }^{32}$. Por lo tanto, dotar de interactividad a los mensajes es una oportunidad para incrementar la implicación de los consumidores con los mismos que desencadenará efectos positivos desde el punto de vista de la eficacia publicitaria.

\subsection{Colaboración}

El concepto de entornos colaborativos es consustancial al nuevo paradigma sociocultural que se está desarrollando en torno a los denominados medios sociales. Plataformas como Wikipedia ejemplifican la labor productiva en red de los consumidores actuales. Estos entornos generadores de valor en base al trabajo colaborativo están impregnando cada vez más áreas de la economía productiva hasta el punto de que se habla ya de los negocios en enjambre ${ }^{33}$ como de un nuevo paradigma de mercado que puede incrementar la productividad y aportar importantes ventajas competitivas. Desde el marco de las comunicaciones publicitarias también se ha explorado el importante papel que pueden desarrollar los consumidores como colaboradores de la producción y difusión de estas comunicaciones. La figura del prosumidor y su importante papel en las acciones de marketing viral ${ }^{34}$ han trazado nuevos caminos y oportunidades para desarrollar comunicaciones publicitarias que

30 Steuer, J. (1992): «Defining Virtual Reality: Dimensions Determining Telepresence», Journal of Communication, 42 (4), 73-93, 84.

31 PÉREZ, C. (2006): «La implicación del consumidor en la adquisición de bienes y servicios», ESIC Market, $\mathrm{N}^{\circ} 123$, pp. 93-113.

32 Andrews, J. C., Durvasula, S. y AKhter, S. H. (1990): «A Framework for Conceptualizing and Measuring the Involvement Construct in advertising Research», Journal of Advertising, 19 (4), 27-40.

33 GLOOR, P. A. y COOPER, S. M. (2007): «Los nuevos principios de un negocio en enjambre», Harward-Deusto Business Review, $\mathrm{N}^{\circ} 162$ (Noviembre), 60-66.

34 MARTí, J. (2006): «Los contenidos publicitarios y el nuevo consumidor de medios digitales: del consumer al prosumern, comunicación en el III Congreso On-line - Observatorio para la cibersociedad, http://www.cibersociedad.net/congres2006/gts/comunicacio.php?\&id=259 Web visitada el 2/1/2009. 
cuentan con el compromiso de los consumidores. Un compromiso que asume que la relación con el socio de un intercambio es suficientemente importante como para hacer el máximo esfuerzo por mantenerla ${ }^{35}$. Un compromiso que ha sido analizado como un constructo multidimensional en el que intervienen tanto elementos cognitivos como afectivos y conativos y que en su dimensión afectiva, implica un vínculo emocional, un sentimiento de identificación y una implicación con la organización, que conduce a un deseo de mantener la relación con la empresa a lo largo del tiempo ${ }^{36}$. Es el tipo de compromiso que se puede observar en los consumidores que se hacen fan de una marca ${ }^{37}$; que desarrollan comunicaciones publicitarias para esa marca; y que tratan de captar nuevos fans para esa marca. Es el caso del anuncio amateur, de 59 segundos de duración, creado con Macromedia ${ }^{\circledR}$ Flash por George Master, un profesor de secundaria de los EE.UU. y fan de Apple, con el objetivo de rendirle un homenaje al iPod.

\subsection{Reducción de costes}

No menos importante que el resto de factores, los medios digitales han eliminado la importante barrera económica que separaba a diferentes tipos de anunciantes. La publicidad en Internet, por ejemplo, frente a otros medios de masas, ha implicado una reducción de costes que ha hecho accesible el medio a todo tipo de anunciantes. Cualquiera de las herramientas disponibles para los anunciantes en Internet (campaña de banners, campaña de email marketing, posicionamiento en buscadores, etc.) ofrece unos desembolsos mínimos asequibles por cualquier anunciante (incluida una Pyme o incluso un autónomo). Es cierto que acciones especiales (por ejemplo la campaña de advertainment The Hire, desarrollada por BMW) pueden suponer costes similares a los de una gran campaña de medios que incluya spots televisivos $^{38}$, pero este techo alto de gasto en una campaña en Internet no implica que no puedan desarrollarse acciones a unos costes ínfimos en comparación con las grandes campañas de medios de masas como la radio, prensa o televisión. Desde este punto de vista Internet ha eliminado las barreras de entrada al mundo de las comunicaciones de marketing a numerosos anunciantes que veían restringidas sus acciones en esta área a pequeños patrocinios locales, al uso del merchandising o a la edición de catálogos y otros formatos gráficos dirigidos al buzoneo, etc.

La mayor oportunidad que representa este factor radica pues en el incremento de la competitividad para todo tipo de anunciantes. En Internet, si pensamos

\footnotetext{
35 Morgan, R. M. y Hunt, S. D. (1994): «The commitment-trust theory of relationship marketing», Journal of Marketing, 58 (3), 20-38.

36 Pritchard, M. P., Havitz, M. E. y Howard, D.R. (1999): «Analyzing the commitment-loyalty link in service contexts», Journal of the Academy of Marketing Science, 27 (3), 333-348.

37 ATKIn, D. (2005): El culto a las marcas, Barcelona, Robin Book; MARTí, J. y MuÑOZ, P. (2008): Engagement Marketing: una Nueva Publicidad para un Marketing de Compromiso, Madrid, Finantial Times/Prentice Hall.

38 MARTí, J. (2011): Marketing y Publicidad en Internet. Básico. $2^{\mathrm{a}}$ Ed., Madrid, Starbook.
} 
especialmente en medios sociales como Youtube, todo anunciante puede desarrollar no sólo una campaña de spots sino incluso su propio canal de televisión (BrandTV). Las débiles barreras de entrada económicas a la publicidad en Internet han democratizado sin duda alguna la publicidad entre todo tipo de anunciantes (incluidos los autónomos y freelancers que utilizan el medio para realizar marketing personal). Buena prueba de ello es el emergente mercado de las empresas que ofrecen servicios de desarrollo y mantenimiento de sitios web en base a plantillas y tarifas planas (como la empresa alemana 1\&1). Del mismo modo, otros medios como la telefonía móvil ofrecen herramientas de marketing móvil (campañas de SMS, aplicaciones publicitarias o mobapps) a unos costes asequibles por cualquier anunciante.

\subsection{Alcance}

Internet ha posibilitado el alcance de audiencias internacionales como no había sido posible hasta su aparición. Una página web de una marca puede ser accedida desde cualquier parte del mundo facilitando la comunicación y detección de oportunidades de negocio a nivel internacional (a cambio de unos pequeños costes adicionales como es la traducción de los contenidos a uno o dos idiomas). En un contexto de creciente internacionalización de los mercados, este aumento del alcance de las comunicaciones de marketing (incluida la publicidad) puede permitir el posicionamiento y la detección de nuevas oportunidades de negocio en nuevos mercados. En el contexto de las comunicaciones de marketing integradas ${ }^{39}$ y de una perspectiva glocal de los negocios (contemplado procesos como la deslocalización y el outsourcing pero también las economías de escala), el alcance de Internet facilita además la adaptación de las comunicaciones a diferentes contextos, mercados y segmentos de consumidores. Esta escalabilidad, que se beneficia de las sinergias (especialmente en el caso de las multinacionales) que se producen como consecuencia de actuar en diferentes mercados, permite no sólo reproducir casos de éxito o estrategias en diferentes mercados sino desarrollar estrategias globales desde un principio. Estas campañas globales de comunicación suelen iniciarse en Internet, anticipando e incluso despertando el interés de los consumidores sobre las mismas cuando llegan a otros medios. Esto es algo que puede observarse en las campañas de promoción de estrenos cinematográficos, en las que se utiliza el alcance de Internet para llegar a audiencias internacionales y retroalimentar la campaña con las reacciones de los consumidores en los diferentes mercados ${ }^{40}$.

39 Schultz, D. E. y Kitchen, P.J. (2000): Communicating Globally: An Integrated Marketing Approach. Nueva York, Macmillan Basingstoke.

40 MARTí, J. (2011): Marketing y Publicidad en Internet. Básico. $2^{\text {a }}$ Ed., Madrid, Starbook. 


\section{Conclusiones}

El entorno publicitario actual plantea importantes retos para el desarrollo de comunicaciones publicitarias eficaces. El impacto que las nuevas tecnologías han tenido en la práctica publicitaria plantea tantos problemas técnicos como conceptuales que desafían a los profesionales actuales. Desde el punto de vista técnico, la fragmentación de las audiencias obliga a replantear las estrategias y metodologías que permitan: 1) alcanzar de forma más eficaz al público al que se dirigen esas comunicaciones (y que se encuentra disperso entre múltiples medios y soportes), y 2) utilizar los lenguajes y mensajes apropiados para cada medio y soporte. Por otra parte, esta multiplicidad de medios y la creciente saturación publicitaria que le acompaña, obliga a: 1) encontrar nuevos espacios no saturados publicitariamente, y 2) ofrecer nuevas propuestas de valor de las comunicaciones publicitarias (por ejemplo, entretenimiento) que sean capaces de captar y retener la atención del consumidor. A su vez, la popularización del software de edición digital, ofreciendo resultados casi profesionales, desafía la propiedad y el control de las marcas sobre unas comunicaciones publicitarias en las que el apropiacionismo y el intrusismo (bien intencionado o no) pueden generar confusión, equívocos y distorsiones en torno a las marcas y sus mensajes. La pérdida del control sobre unos mensajes, que ni siquiera pueden haber sido iniciados por las propias marcas, amenaza con diluir o malversar la identidad, los valores y los objetivos que se pretenden transmitir con estas comunicaciones. Esta situación es agravada por un contexto comunicativo en el que, a través de Internet, las comunicaciones iniciadas por cualquier consumidor son capaces de alcanzar una difusión global sin precedentes en los modelos comunicativos anteriores (fuertemente jerarquizados y restrictivos).

Por otra parte, este mismo entorno publicitario facilita a los profesionales de las comunicaciones de marketing una riqueza de medios que les permite elaborar múltiples mensajes que se ajusten mejor a la conveniencia de los consumidores: mensajes para ser consumidos a través de sus teléfonos móviles mientras esperan el autobús; mensajes para ser consumidos en sus emails mientras utilizan sus ordenadores; mensajes para ser consumidos en televisión... Además, el manejo de enormes bases de datos que contienen información y perfiles detallados de los consumidores así como un creciente contexto de movilidad, les permite dirigir mensajes personalizados a sus intereses y necesidades en tiempo real. Se incrementa de ese modo la relevancia del mensaje para el consumidor. Así, se puede enviar un SMS con una oferta de un dispositivo tecnológico que ofrece un distribuidor cercano al lugar al que se encuentra el consumidor después de conocer que ese consumidor ha estado realizando búsquedas online sobre precios de ese mismo dispositivo.

Asimismo, la interactividad permite desarrollar mensajes con los que obtener retroalimentación instantánea de la respuesta de los consumidores al mensaje. Esta retroalimentación facilita la toma de decisiones en relación a la eficacia que está teniendo el mensaje y, en su caso, aplicar rápidamente las medidas correctoras que 
la incrementen. A su vez, la interactividad posibilita una mayor implicación del consumidor con el mensaje. Frente a la actitud pasiva que éste adopta en los mensajes no interactivos, los mensajes interactivos demandan mayores recursos cognitivos que pueden facilitar e incrementar el procesamiento de la información del mensaje. Además, en el nuevo contexto de la cultura de la colaboración (fenómenos wiki, blogs y microblogs, comunidades y grupos de interés en redes sociales, etc.) los profesionales de la publicidad pueden encontrar en el consumidor a un importante aliado comprometido con la creación y difusión de mensajes publicitarios de aquellas marcas que le aportan valores y significados importantes para él. Los fans de las marcas no sólo serán aliados leales frente a la competencia sino que intentarán captar a nuevos fans para que se unan a ellos.

Finalmente, las débiles barreras de entrada económicas al desarrollo de acciones de publicidad en medios como Internet o la telefonía móvil han incrementado la competitividad de numerosas empresas que son ahora capaces de abrirse paso a un entorno mediático hasta ahora acotado a las grandes corporaciones.

Así pues, las nuevas tecnologías de la información, en constante evolución, parecen ofrecer más oportunidades que retos para la comunicación publicitaria. No obstante estas oportunidades implican una profunda revisión de los modelos, metodologías y formatos con los que se deben desarrollar las comunicaciones publicitarias actuales. La utilización de nuevos modelos (modelos colaborativos) y formatos (advertainment, advergaming, contenidos generados por los consumidores, etc.) implica una redefinición de las funciones y los objetivos de la publicidad actual. En un contexto informativo en el que el consumidor ha ganado en independencia a la hora de acceder a la información (medios no jerarquizados), en el que ha ido adquiriendo experiencia como consumidor (siendo por tanto menos permeable a los intentos persuasivos) y en el que es capaz de informar a otros consumidores acerca de marcas, productos y servicios (actuando como prescriptor y nueva fuente de información), parece permitente la reflexión sobre cuál debe ser la función de la publicidad actual. Este nuevo contexto publicitario implica también una redefinición de otros conceptos como el de marca. Unas marcas que, para desarrollar comunicaciones publicitarias en estos nuevos contextos, deben de ser más permeables a la acción de los consumidores (con los riesgos que esto implica). Unas marcas más abiertas a los consumidores. Y unas marcas que, en este proceso de apertura, deben ser también más transparentes, más honestas y más responsables. Una responsabilidad que también se le debe exigir a un consumidor que no siempre ha sido transparente, honesto y responsable con las marcas. Esta colaboración y compromiso mutuo marca-consumidor, que puede verse plasmada en las comunicaciones publicitarias, puede asimismo trascender el ámbito de la comunicación e instaurarse en otros momentos y procesos (desde la producción hasta el consumo). En la medida en que estos puntos de encuentro entre marcas y consumidores sean mayores, y los beneficios mutuos también lo sean, quizás se esté empezando a trabajar en nuevos modelos empresariales más productivos y beneficiosos para la sociedad. 


\section{Limitaciones y futuras líneas de investigación}

Este trabajo supone una primera aproximación teórica, desde un marco exploratorio, a los principales retos y oportunidades que el nuevo contexto sociotecnológico plantea a la comunicación publicitaria actual. El trabajo ha permitido identificar las principales debilidades-amenazas y fortalezas-oportunidades de este contexto que permitan desarrollar comunicaciones publicitarias más eficaces. Sin embargo, pese a su valor teórico y exploratorio, adolece de constataciones empíricas que verifiquen o desmientan los supuestos teóricos planteados. En este sentido, trabajos posteriores deberían desarrollar el marco teórico requerido para testar empíricamente estos supuestos (adoptando tanto el punto de vista del emisor como del receptor de las comunicaciones publicitarias). Asimismo futuros trabajos deberían ampliar el enfoque socio-tecnológico adoptado en este trabajo. Otros factores y fuerzas del mercado como los factores que moderan las relaciones anuncianteagencia de publicidad, las metodologías de selección de proyectos comunicativos (concursos, etc.) o la evolución económica de los mercados, también están afectando el modo de desarrollo de unas comunicaciones publicitarias más eficaces.

Por otra parte, los medios y formatos tradicionales todavía gozan de un peso preponderante en cuanto a inversión y, por tanto, praxis comercial. Esta coexistencia con los nuevos medios y formatos está generando sinergias pero también conflictos. ¿Cómo se está produciendo esta transición entre lo viejo y lo nuevo en el marco de los modelos de eficacia publicitaria planteados en la actualidad? ¿Cuáles son los principales factores de resistencia (tanto directivos como formativos, tecnológicos o económicos) que impiden, dificultan, o no hacen viable en la praxis comercial, esta integración?

Todas estas cuestiones planteadas nos permiten vislumbrar futuras líneas de investigación que permitan mejorar la efectividad y recepción de los mensajes publicitarios y adaptarlos a un macro entorno tecnológico cambiante y en constante evolución.

\section{Referencias bibliográficas}

Andrews, J. C., Durvasula, S. y AKhter, S. H. (1990): «A Framework for Conceptualizing and Measuring the Involvement Construct in advertising Research», Journal of Advertising, 19 (4), 27-40.

ATKIN, D. (2005): El culto a las marcas, Barcelona, Robin Book.

BuZzI, G. A. (Ed.) (2009): El modelo de la Nueva Agencia, http://creativecommons.org/ licenses/by-nc-nd/2.5/ar/ Web visitada el 6/3/2011

CAYwood, C. (1997): «Integrated Marketing Communication», Proceedings de la Seoul International Advertising Conference. Seúl, Korea Federation of Advertising Associations. 
Culnan, M. J. (1985): «The dimensions of perceived accessibility to information: Implications for the delivery of information systems and services», Journal of the American Society for Information Science, 36, 302-308.

DAFT, R. L. y LENGEL, R.H. (1986): «Organizational information requirements, media richness and structural design», Management Science, 32 (5), 554-571.

FISKE, J. (1992): «The Cultural Economy of Fandom», En Lewis, Lisa A. (Ed.): The Adoring Audience. Londres, Routledge.

GloOR, P. A. y COOPER, S. M. (2007): «Los nuevos principios de un negocio en enjambre», Harward-Deusto Business Review, No162 (Noviembre), 60-66.

Goldhaber, M. H. (1997): «The Attention Economy and the Net», First Monday, 2 (4).

KatZ, E., Gurevitch, M. Y HAAs, H. (1973): «On the Use of the Mass Media for Important Things», American Sociological Review, 38 (2), 164-181.

KIM, J.A., CHRIS, T. y KARDES, F. R. (1996): «An Investigation of the Mediational Mechanisms Underlying Attitudinal Conditioning», Journal of Marketing Research, 33 (Agosto), 318-328.

LeHU, J. M. (2007): Branded Entertainment: Product Placement \& Brand Strategy in the Entertainment Business, Kogan Page, Londres y Filadelfia.

LEVINSON, J. C. (2001): «Integrated Marketing», Executive Excellence, 18 (1)1, 9-10

MacMillan, S. J. y HwANG, J. S. (2002): "Measures of Perceived Interactivity: An Exploration of the Role of Direction of Communication, User Control, and Time in Shaping Perceptions of Interactivity», Journal of Advertising, 31 (3), 29-57.

MARKMAN, K. M. (2005): «Star Trek, Fan Film, and the Internet: Possibilities and Constraints of Fan-Based Vernacular Cultures», ponencia presentada en la Popular Communication Division de la Annual Convention of the International Communication Association, 30 de Mayo, New York, NY.

MARTí, J. (2002): Publicidad y entretenimiento en la web: Estrategias, Formatos y Tipologías de Advertainment. Tesis Doctoral, Universidad Politécnica de Valencia.

MARTí, J. (2006): «Los contenidos publicitarios y el nuevo consumidor de medios digitales: del consumer al prosumer», comunicación en el III Congreso On-line - Observatorio para la cibersociedad, http://www.cibersociedad.net/congres2006/gts/comunicacio.php ?\&id=259 Web visitada el 2/1/2009.

MARTí, J. (2010): Funny Marketing: consumidores, entretenimiento y comunicaciones de marketing en la era del branded entertainment, Madrid, Wolters-Kluwer.

MARTÍ, J. (2011): Marketing y Publicidad en Internet. Básico. $2^{a}$ Ed., Madrid, Starbook.

MARTí, J. y MuÑOZ, P. (2008): Engagement Marketing: una Nueva Publicidad para un Marketing de Compromiso, Madrid, Finantial Times/Prentice Hall.

MORGAN, R. M. y HUNT, S. D. (1994): «The commitment-trust theory of relationship marketing», Journal of Marketing, 58 (3), 20-38.

PAVlou, P. A. y StewART, D. W. (2000): «Measuring the Effects and Effectiveness of Interactive Advertising: A Research Agenda», 1 (1), http://www.jiad.org/vol1/no1/pavlou/index.htm Web visitada el 23/5/2007.

PÉREZ, C. (2006): «La implicación del consumidor en la adquisición de bienes y servicios», ESIC Market, №123, pp. 93-113.

Pritchard, M. P., HAVITZ, M. E. y Howard, D.R. (1999): «Analyzing the commitmentloyalty link in service contexts», Journal of the Academy of Marketing Science, 27 (3), 333-348. 
RIES, A. y RIES, L. (2003): La caída de la publicidad y el auge de las RR.PP., Barcelona, Ediciones Urano (colección Empresa Activa) (1ºdición 2002, HarperCollins).

RodGers, S. y THORSON E. (2000): «The Interactive Advertising Model: How Users Perceive and Process Online Ads», Journal of Interactive Advertising, 1 (1), http://jiad.org/vol1/no1/rodgers Web visitada el 23/6/2007.

Schultz, D. E. y KITCHEN, P.J. (2000): Communicating Globally: An Integrated Marketing Approach. Nueva York, Macmillan Basingstoke.

SouthgATE, D. (2009): «Targeting Online Ads: Aim for the Bulls-eye or Focus on Hitting the Target?», Millward Brown Point of View.

Steuer, J. (1992): «Defining Virtual Reality: Dimensions Determining Telepresence», Journal of Communication, 42 (4), 73-93.

VRAnicA, S. y Terhune, C. (2006): «Mixing Diet Coke and Mentos makes a gusher of publicity», 12 de Junio, B1, http://online.wsj.com/article_print/SB115007602216777 497.html Web visitada el 21/2/2011.

Recibido: 15 de enero de 2012

Aceptado: 29 de octubre de 2012 